\title{
TU/e emonownen

\section{Pressure drop of laminar gas flows in a microchannel containing various pillar matrices}

\section{Citation for published version (APA):}

Vanapalli, S., Brake, ter, H. J. M., Jansen, H. V., Burger, J. F., Holland, H. J., Veenstra, T. T., \& Elwenspoek, M. C. (2007). Pressure drop of laminar gas flows in a microchannel containing various pillar matrices. Journal of Micromechanics and Microengineering, 17(7), 1381-1386. https://doi.org/10.1088/0960-1317/17/7/021

DOI:

10.1088/0960-1317/17/7/021

Document status and date:

Published: 01/01/2007

\section{Document Version:}

Publisher's PDF, also known as Version of Record (includes final page, issue and volume numbers)

\section{Please check the document version of this publication:}

- A submitted manuscript is the version of the article upon submission and before peer-review. There can be important differences between the submitted version and the official published version of record. People interested in the research are advised to contact the author for the final version of the publication, or visit the $\mathrm{DOI}$ to the publisher's website.

- The final author version and the galley proof are versions of the publication after peer review.

- The final published version features the final layout of the paper including the volume, issue and page numbers.

Link to publication

\section{General rights}

Copyright and moral rights for the publications made accessible in the public portal are retained by the authors and/or other copyright owners and it is a condition of accessing publications that users recognise and abide by the legal requirements associated with these rights.

- Users may download and print one copy of any publication from the public portal for the purpose of private study or research.

- You may not further distribute the material or use it for any profit-making activity or commercial gain

- You may freely distribute the URL identifying the publication in the public portal.

If the publication is distributed under the terms of Article 25fa of the Dutch Copyright Act, indicated by the "Taverne" license above, please follow below link for the End User Agreement:

www.tue.nl/taverne

Take down policy

If you believe that this document breaches copyright please contact us at:

openaccess@tue.nl

providing details and we will investigate your claim. 


\title{
Pressure drop of laminar gas flows in a microchannel containing various pillar matrices
}

\author{
S Vanapalli, H J M ter Brake, H V Jansen, J F Burger, \\ H J Holland, T T Veenstra and M C Elwenspoek \\ MESA+ Institute of Nanotechnology, University of Twente, 7500 AE Enschede, \\ The Netherlands \\ E-mail: s.vanapalli@ewi.utwente.nl
}

Received 25 April 2007, in final form 18 May 2007

Published 14 June 2007

Online at stacks.iop.org/JMM/17/1381

\begin{abstract}
The pressure drop of gas flows in a microchannel filled with a dense pillar matrix was investigated with specific attention to a pillar shape. Pillars of height $250 \mu \mathrm{m}$ and aspect ratio of about 10 were etched in silicon using an optimized Bosch deep reactive ion etching process. The pressure drop head-loss coefficient due to compression and expansion of gas at the inlet and outlet of the pillar matrix was estimated to be about 1.4 for an opening ratio of 10. A comparison of friction factor correlations for circular pillar cross-sections agreed rather well with the correlations proposed for the macroscale. Experimentally determined friction factor correlations for several pillar cross-sections for Reynolds numbers in the range of 50-500 are presented. Among the various pillar cross-sections considered, sine-shaped pillars have the lowest friction factor. These pillar structures with low pressure drop but a rather large wetted area can be used quite effectively as regenerative materials enabling the development of microcryocoolers.
\end{abstract}

\section{Introduction}

Over the past decade, forced flow across a matrix of micro pillars has been a subject of interest in many applications such as micro reactors [1], micro heat sinks [2], etc. These pillar matrices can also be used as heat exchangers, such as cross flow heat exchanger [3] and counter flow heat exchangers [4] for continuous flows or as a regenerator $[5,6]$ for oscillating flows. The increase in the areato-volume ratio at the smaller scale enhances the heat transfer but it also increases the pressure drop due to small openings. Numerical simulations done by Radebaugh and O'Gallagher [7] predict of smaller hydraulic diameter regenerators to efficiently operate regenerative cryocoolers at high frequency. This would enable miniaturization of the regenerator and the development of microcryocoolers for on-chip cryogenic cooling. We have experimentally demonstrated this theoretical prediction on a mesoscale cooler [8]. Conventional regenerative cryocoolers operating at $80 \mathrm{~K}$ use stainless steel wire screens as the regenerative material. However, currently there is a limitation on the finest screen (the smallest hydraulic diameter is about $30 \mu \mathrm{m}$ ) commercially available. Ruhlich and Quack [6] have performed numerical simulations on several geometrical shapes for regenerators and concluded that there could be better alternative geometries to screens. Considering microcryocooler applications and using microsystem technology for production, we have considered investigating micro pillars embedded in a flow channel for developing a micro-regenerator.

The main purpose of this study is to identify a pillar shape with low hydraulic (pressure drop) and thermal (heat transfer) resistance for gas flow in regenerators. As a first step in identifying the optimum geometry, pressure drop characteristics of various pillar shapes were investigated. For a regenerator, the contact area between the gas and the material should be large with low material heat conduction losses in the flow direction. In order to achieve this, the aspect ratio of pillars should be rather large which allows most of the interaction of gas to occur with the pillars and not the supporting walls that make up the fluidic channel. Several studies on macroscale heat exchangers consisting of a bank (matrix) of circular pillars were performed and empirical 
Table 1. Geometries and corresponding friction factors considered in the investigation. All dimensions are in microns.

\begin{tabular}{|c|c|c|c|c|c|c|}
\hline Geometry & Shape & Hydraulic diameter, $D_{h}$ & Smallest gap & $a$ & $b$ & Friction factor correlation, $f$ \\
\hline Circle & & 84.7 & 21.8 & 28.2 & - & $\begin{array}{l}\text { Staggered, } f=70.20 R e^{-0.44} \\
\text { Aligned, } f=103.50 R e^{-0.64}\end{array}$ \\
\hline Square & $a$ & 75.0 & 25.0 & 25.0 & - & $\begin{array}{l}\text { Staggered, } f=96.50 R e^{-0.55} \\
\text { Aligned, } f=183.02 R e^{-0.90}\end{array}$ \\
\hline Ellipse & & 34.4 & 18.6 & 16.3 & 49.0 & $f=26.98 R e^{-0.82}$ \\
\hline Eye & & 66.8 & 20.2 & 17.4 & 52.4 & $f=87.10 R e^{-0.80}$ \\
\hline Rhombus & & 58.3 & 20.5 & 20.5 & 61.0 & $f=175.20 R e^{-0.94}$ \\
\hline Sine & & 23.2 & 18.0 & 15.6 & 80.0 & $f=29.65 R e^{-0.94}$ \\
\hline
\end{tabular}

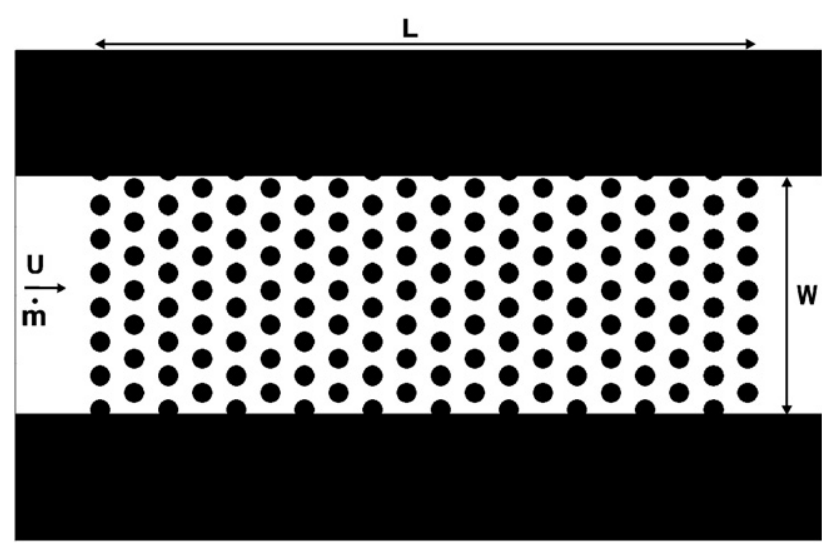

Figure 1. Schematic of a test sample with several pillars embedded in a microchannel. The length $L$ is $1 \mathrm{~mm}$ and the width $W$ is $0.35 \mathrm{~mm}$.

correlations were summarized by Zukauskas and Ulinskas [10]. Introductory numerical simulation on various shapes of regenerators was reported by Ruhlich and Quack [6]. They conclude that the optimum geometry consisted of slim elements in a staggered (overlapping) arrangement. However, the authors have not provided the geometrical and friction factor data for all the shapes investigated. In this paper, we follow an experimental approach of measuring pressure drop across various shapes of pillar matrices. The experimental results were compared with the macro correlations for circleshaped pillars. Rectangular channels were also considered to determine the head-loss coefficient attributed to compression and expansion of gas at the inlet and outlet of the pillar matrix, for higher opening ratios.

\section{Definitions and design}

A schematic cross-section of a test sample is shown in figure 1. The pillar structures lie in a rectangular channel perpendicular to the direction of flow. Circle, square, rhombus, elliptical, eye (formed by intersection of two circles) and sine-shaped pillar cross-sections (see table 1) were investigated in this study.
For the circle and square pillar cross-sections, aligned and staggered patterns (see the inset in figure 6) were used and for the rest only staggered patterns were investigated. The crosssectional area and the height $h$ of all the pillar shapes were kept constant, which yields a constant pillar material volume $V_{m}$ and a constant porosity of the matrix $\varepsilon$ which is defined as

$$
\varepsilon=1-V_{m} / V,
$$

where $V$ is the total volume of the rectangular channel containing the pillars. The dimensions of all pillar crosssections are shown in table 1 . The porosity of the pillar matrices was 0.75 . The longitudinal (in the flow direction) pitch $P_{L}$ and the transverse pitch $P_{T}$ (see the inset in figure 6) were kept constant equal to $50 \mu \mathrm{m}$ for all the pillar crosssections. Several definitions for experimental correlations of pressure drop across a tube bundle matrix can be found in the literature. The pressure drop $\Delta P$ was related to the friction factor $f^{*}$ by Zukauskas and Ulinskas [10] as

$$
\Delta P=f^{*} N \frac{1}{2} \rho u_{\max }^{2},
$$

where $N$ is the number of tube rows, $u_{\max }$ is the maximum velocity in the matrix and $\rho$ is the density of the gas. However, in regenerator analysis [5-7] and also in numerical tools for a regenerator such as REGEN [12,13], a definition based on the theory of porous media was used and is given by [14]

$$
\Delta P=\frac{1}{2} \rho u_{m}^{2}\left(f \frac{L}{D_{h}}+K\right),
$$

where $f$ is the friction factor and $L$ is the length of the channel. The mean velocity $u_{m}=u / \varepsilon, u=\dot{m} / \rho A_{f}$ with $\dot{m}$ being the mass flow rate of the gas, $\rho$ the gas density and $A_{f}$ the flow area equal to the width $W$ times the height $h$ of the channel. The factor $K$ accounts for the head loss due to compression of fluid when it encounters a pillar matrix and expansion of fluid when it flows out of the pillar matrix. To investigate these losses in microscale and to compare them with mesoscale studies, a series of parallel rectangular channels were made and investigated. The hydraulic diameter $D_{h}$ is defined as

$$
D_{h}=4 \varepsilon V / A_{w} .
$$



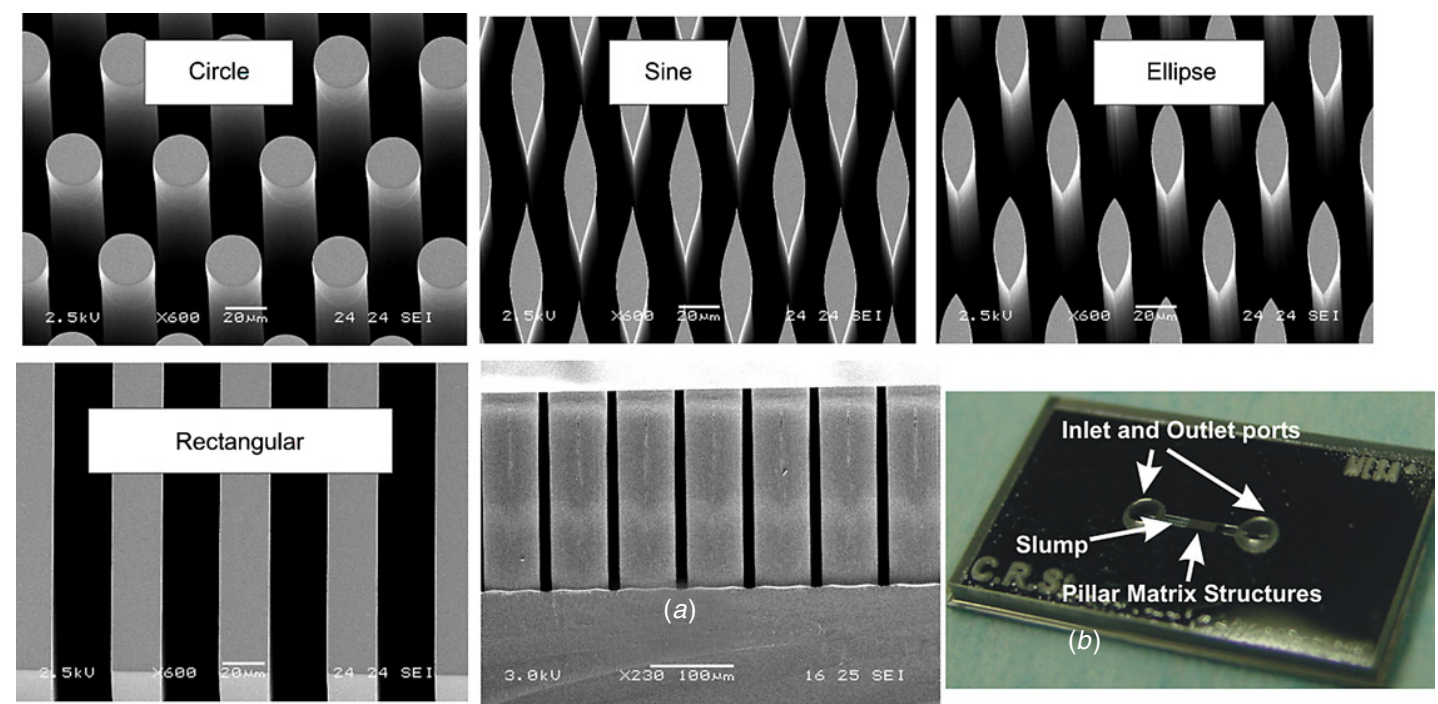

Figure 2. SEM pictures of the circle, sine, ellipse pillar matrix and rectangular channels. (a) Cross-section of the pillars showing vertical walls. $(b)$ Test sample showing inlet and outlet ports for fluidic connections and the pillar matrix.

(This figure is in colour only in the electronic version)

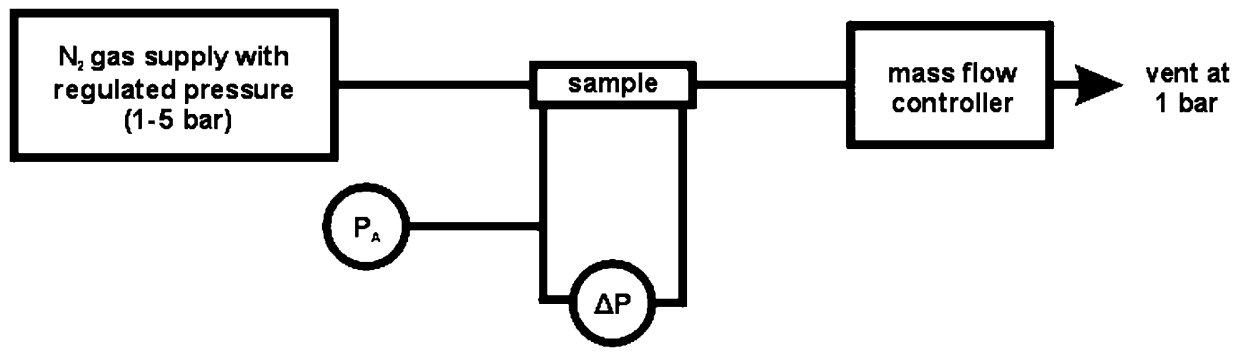

Figure 3. Schematic of the experimental setup. The mass flow and the absolute pressure could be set with this configuration.

where $A_{w}$ is the wetted area of the pillars. The friction factor is usually a function of the Reynolds number and is expressed as

$$
f=C / R e^{m} .
$$

The friction coefficient $C$ is geometry dependent and the exponent $m$ depends on the flow regime and other fluidic effects. For a laminar, fully developed, incompressible flow the exponent $m=1$. The Reynolds number $R e$ is given by

$$
R e=\frac{\rho u_{m} D_{h}}{\mu} \text {. }
$$

Here $\mu$ is the dynamic viscosity which is a strong function of the temperature as is the gas density. The temperature in the regenerator varies along the length $L$ from ambient (about $300 \mathrm{~K})$ at the warm end to cryogenic temperature $(<120 \mathrm{~K})$ at the cold end. Hence, the Reynolds number also varies along the length of the regenerator. Micro regenerative cryocoolers that operate at high frequency $(120-1000 \mathrm{~Hz})$ have an optimum gas cross-sectional area to mass flow (equal to $1 / \rho U_{m}$ ) in the range of $0.02-0.07 \mathrm{~m}^{2} \mathrm{~s} \mathrm{~kg}^{-1}[8,9]$, and for a hydraulic diameter less than $30 \mu \mathrm{m}$, the region of interest of the Reynolds number is in the range between $\operatorname{Re} \sim 50$ and 250 .

\section{Experimental details}

The high aspect-ratio pillar structures were etched in silicon using a customized Bosch deep reactive ion etching process.
The roughness of the surface is less than about $0.3 \mu \mathrm{m}$. The accuracy in determining the Reynolds number and the friction factor depends on the accuracy with which the geometrical dimensions and flow parameters can be determined. All the lateral geometrical dimensions were determined using an optical digital microscope which has a dimensional uncertainty of about $0.1 \mu \mathrm{m}$. The vertical height of the pillars was investigated under SEM with a cleaved sample an example of which is shown in figure $2(a)$. The height variation between different pillar structures is less than $5 \mu \mathrm{m}(<2 \%)$. A silicon wafer with channels containing pillars was closed by anodically bonding a glass wafer with holes sand blasted for fluidic connection. One of the diced samples is shown in figure $2(b)$. The experimental test setup is schematically shown in figure 3 and consists of a test sample, a nitrogen gas bottle with a pressure regulator, an absolute pressure sensor (range $0.7 \mathrm{MPa}$, accuracy $\sim 1 \%$ ), a differential pressure sensor (range $0.1 \mathrm{MPa}$, accuracy $\sim 1 \%$ ) and a mass flow controller (range $0-30 \mathrm{mg} \mathrm{s}^{-1} \mathrm{~N}_{2}$, accuracy $\sim 0.15 \%$ ). With this configuration the absolute pressure could be adjusted with the pressure regulator and at the same time the mass flow through the valve could be adjusted with the flow controller. The experimental procedure consists of setting the mass flow to a certain value and then the inlet pressure was set with the pressure regulator. Once the flow has stabilized the pressure drop values were recorded. This procedure was repeated for 


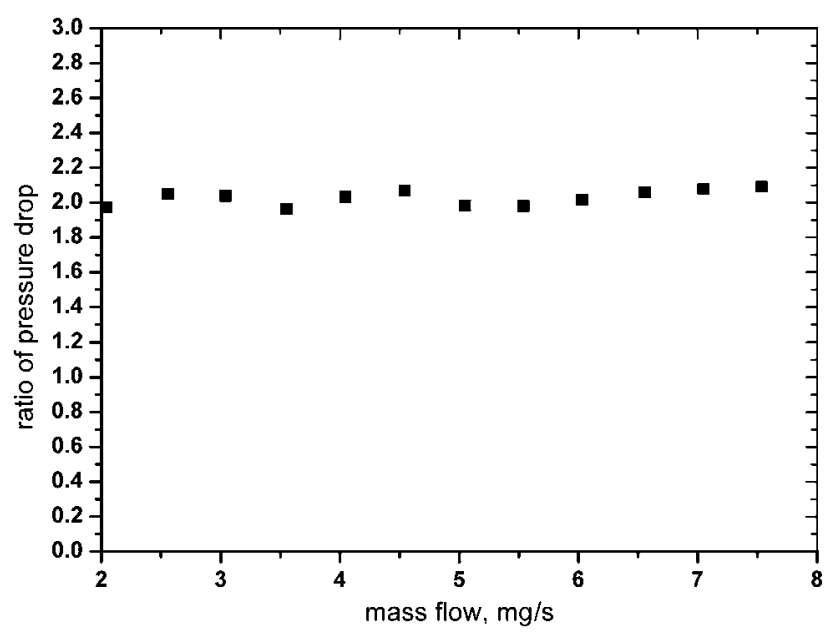

Figure 4. Plot of the ratio of the pressure drop between samples 1 and 2. Sample 2 has twice the diameter of the circle, pitch of the matrix, length and width of sample 1 . The ratio is close to 2.0 indicating very small influence of the first and last row of pillars on the flow development and most of the losses are frictional.

different values of mass flow in the range of $1-8 \mathrm{mg} \mathrm{s}^{-1}$. The gas properties were evaluated at an ambient temperature of about $295 \mathrm{~K}$. Experiments were performed on all the samples described in table 1 and also on rectangular channels. The absolute pressure $P_{0}$ at the inlet to the test device is kept at $0.5 \mathrm{MPa}$.

The inlet and outlet slumps indicated in figure $2(b)$ also contribute to the pressure drop measured at the inlet and outlet ports of the sample. The total length of the slumps was about $8 \mathrm{~mm}$ and the hydraulic diameter was $0.5 \mathrm{~mm}$ (two times height of the channel). A test sample with no pillars was used to simulate the condition of having only inlet and outlet slumps. The measured pressure drop between the inlet and outlet ports of this sample was lower than the resolution of the pressure sensor in the mass flow range of $1-8 \mathrm{mg} \mathrm{s}^{-1}$. Hence the contribution of the slumps to the pressure drop can be neglected. To estimate the effect of flow development in the first and last rows of pillars, a test sample (circle aligned pattern) was designed with the diameter of the circle, pitch of the matrix, length and width of the channel twice that of the original one. The two samples were tested and the resulting ratio of pressure drop as a function of mass flow is shown in figure 4 . The ratio was close to 2 , showing less influence of flow development in the first and last few rows of pillars compared to the frictional losses.

\section{Results}

Rectangular microchannels were first tested to compare with theoretical predictions for macrosystems. The coefficient $K$ in equation (3) is given by Blevins [15] for rectangular channels and is defined separately for the inlet $K_{\text {in }}$ and exit $K_{\text {out }}$. The coefficient $K$ is the sum of $K_{\text {in }}$ and $K_{\text {out }}$. For a fully developed laminar flow in rectangular channels the friction factor $f=$ $C / \operatorname{Re}(m=1$ in equation (5)). The friction coefficient $C$ for rectangular channels was given by [15]

$$
C=\frac{64}{\frac{2}{3}+\frac{11}{24} \frac{o}{h}\left(2-\frac{o}{h}\right)},
$$

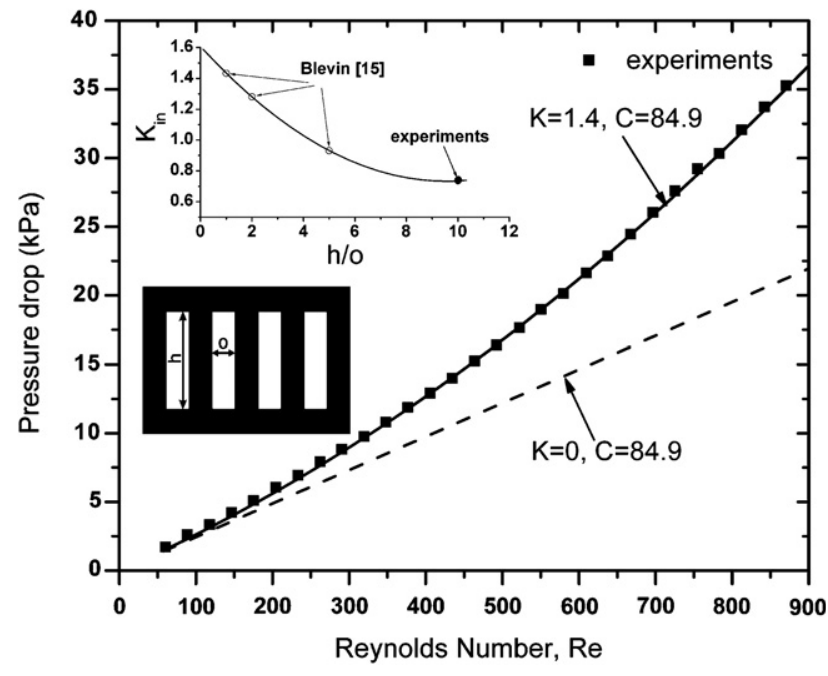

Figure 5. Pressure drop measurement on rectangular channels with a fit to the measurements. From this fit the inlet resistance coefficient $K_{\text {in }}$ is determined. Theoretical pressure drop (equation (3)) without considering the inlet and exit losses is also plotted. In the inset $K_{\text {in }}$ is plotted for the available data [15] and from that determined from experiments for the aspect ratio of 10 . A cross-section of the rectangular channels perpendicular to the gas flow is also shown.

where $h$ is the height of the channel and $o$ is the width of the opening (as shown in figure 5). In our case the opening ratio $h / o$ is 10 , so $C$ equals 84.9 . The outlet resistance coefficient $K_{\text {out }}$ is given by [15]

$$
K_{\text {out }}=\frac{2 A_{1}}{A_{2}}\left(\alpha_{1}-\alpha_{2} \frac{A_{1}}{A_{2}}\right),
$$

where $A_{1}$ is the flow area of the channel and $A_{2}$ is the area it expands to. The parameters $\alpha_{1}$ and $\alpha_{2}$ are constants, which for a laminar flow are equal to 1.33 [15]. In our case $A_{1} / A_{2}=0.5$ so $K_{\text {out }}=0.665$. Data on the inlet resistance coefficient $K_{\text {in }}$ are only available for relatively small values of the opening ratio. Since the opening ratio in this study is 10 which was not available in the literature, we would like to find $K_{\text {in }}$ by fitting equation (3) to the experimentally measured pressure drop. In figure 5 , the pressure drop measurement for rectangular channels is plotted as a function of the Reynolds number. The pressure drop data are fitted taking $C=84.9$ and $K_{\text {out }}=0.665$. The best fit is obtained when $K_{\text {in }}=0.735$. The dependence of $K_{\text {in }}$ on the aspect ratio is shown in the inset of figure 5 with data from [15] and the value from the experimental data for $h / o=10$. The inlet loss coefficient, $K_{\mathrm{in}}$, decreases with increasing aspect ratio. The measured pressure drop through the rectangular microchannels agrees rather well to the theoretical prediction of equation (3). The small dependence of $K_{\text {in }}$ on the opening ratio between 8 and 10 allows the use of $K=1.4$ for all other shapes of the pillar matrices.

Circle aligned and staggered patterns of pillar structures were studied in great detail for macro heat exchanger applications and several correlations were available. Zukauskas and Ulinskas [10] compiled correlations from several studies which were numerically shown to be valid for even a lower Reynolds number by Ghosh Roychowdhury 


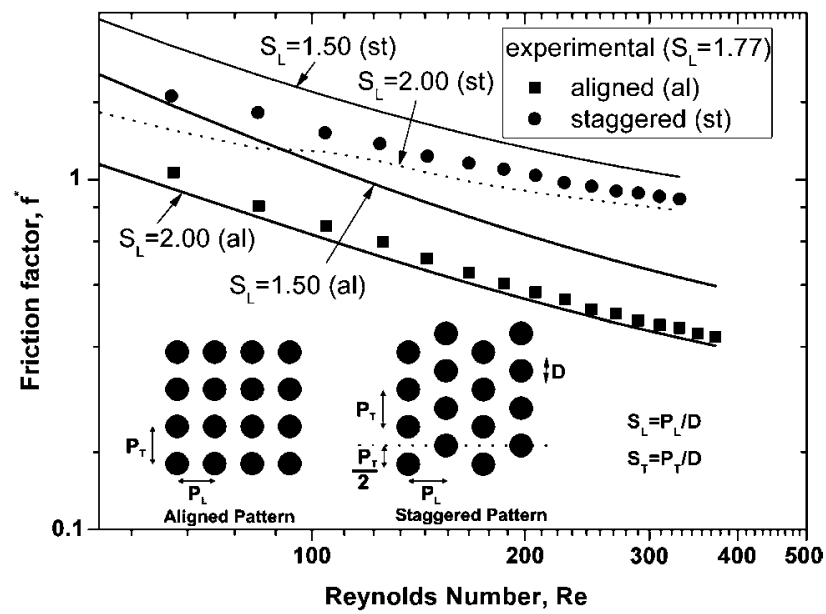

Figure 6. Comparison of experimentally determined friction factors for circle aligned and staggered patterns with that compiled by Zukauskas and Ulinskas [10]. The bold line is the data from [10] for a relative pitch ratio of 1.50 and 2.00 .

et al [16]. Experiments preformed by Kosar et al [11] on micro circular pillar structures have no good agreement with that of conventional macro correlations. However, the aspect ratio of pillars used in their study was about 2 , which is quite small and the interaction of fluid with the top and bottom capping walls cannot be neglected. The aspect ratio of pillars used in this study was about 10 and the experimental results are compared with that compiled by Zukauskas and Ulinskas [10]. The friction factor $f^{*}$ used by Zukauskas and Ulinkas is given by equation (2). The experimentally determined friction factors with the Reynolds number for circle aligned and staggered patterns are shown in figure 6. Zukauskas and Ulinskas [10] defined the relative horizontal pitch $S_{\mathrm{L}}=P_{\mathrm{L}} / D$ and a relative vertical pitch $S_{\mathrm{T}}=P_{\mathrm{T}} / D$, where $D$ is the diameter of the circle. Both relative pitches in our study were 1.77. However, correlations from [10] were available only for the relative pitch equal to 1.5 and 2.0 , which are plotted in figure 6 for both aligned and staggered patterns. The experimentally determined friction factors lie in between the two curves proposed by Zukauskas and Ulinskas. Hence there was no significant deviation in the friction factors in the microscale.

The friction factor $f$ and Reynolds numbers $R e$ for all shapes in table 1 were determined from the experimentally measured pressure drop and mass flow and using equations (3) and (6). The coefficient $K$ was taken to be 1.4. The correlation between the friction factor and Reynolds number is given in table 1 and the data are plotted in figure 7. Circle staggered patterns which are conventionally used in macro heat exchangers have the highest friction factors among all shapes. The reason could be that circle-shaped pillars have significant variation in the cross-sectional area in the direction of the flow which results in velocity changes in flow leading to higher friction factors. Lenticular (slim) elements such as rhombus, eye, ellipse and sine shaped have relatively smaller changes in cross-sectional area compared to circle- and square-shaped pillars. Among the lenticular elements, sine-shaped pillars have a fairly uniform gap (less flow area variation) in the flow direction leading to lower velocity changes and a lower friction

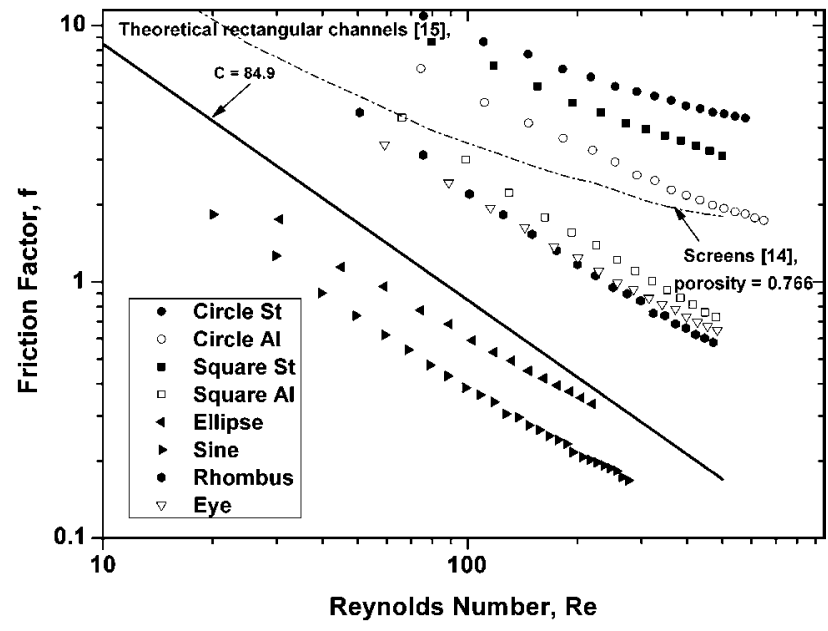

Figure 7. Compiled friction factor data for all the geometrical shapes described in table 1. Data for screens [14] (the Fanning friction factor used in [14] is one fourth of the friction factor $f$, also called the Darcy-Wesisbach friction factor defined in equation (3)) and rectangular channels [15] with porosity 0.5 are also shown. Sine and elliptical pillar cross-sections have friction factors smaller than screens which were the commercially used regenerative material. The slope of friction factor data for the sine cross-section is close to that of theoretical rectangular channels.

factor. Although, rhombus elements have uniform gaps, they have abrupt change in direction of flow at the corners of the pillar, also contributing to a higher friction factor. Ellipse shape has rounded corners and has a lower friction factor compared to rhombus shape but still greater than sine-shaped elements. Friction factor data from Kays and London [14] for stacked screens and rectangular channel data from Blevins [15] are also shown in figure 7 . In the region of interest of Reynolds number between 50 and 250, elliptical and sine patterns have lower friction factor than screens and rectangular channels. The exponent $m$ in equation (5) for sine patterns is about 0.94 and is close to 1.00 for rectangular channels indicating a similar flow behavior.

\section{Conclusions and outlook}

We have experimentally determined the friction factors for gas flow across various pillar cross-sections in the Reynolds number between 50 and 500. The head-loss coefficient $K$ at the inlet and outlet of the rectangular channels, for an opening ratio of 10 was experimentally determined to be about 1.4. Friction factor comparison of circle-shaped pillar matrices with studies on macroscale has rather good agreement, showing no significant microfluidic effects. Sineshaped pillar cross-sections have the lowest friction factor compared to all other pillar cross-sections including screen which is a conventionally used regenerator material. The low friction factor in sine-shaped pillar matrices is attributed to the lower velocity changes because of the almost uniform gap in the flow direction. Further study will be carried out to measure heat transfer coefficients of these pillar matrices to obtain an optimum geometry considering both hydraulic and thermal performance of the pillar matrix. 


\section{Acknowledgments}

The authors acknowledge Meint de Boer for assistance in the cleanroom and fine tuning the Bosch process, and Remco Sanders and Erwin Honderbrink for organizing the experimental setup. This work is funded by the Dutch Technology Foundation (STW) within the '3LN Microcooler' project [TTF.5677].

\section{References}

[1] Srinivas S, Dhingra A, Im H and Gulari E 2004 A scalable silicon microreactor for preferential $\mathrm{CO}$ oxidation: performance comparison with a tubular packed-bed microreactor Appl. Catalysis A 274 285-93

[2] Peles Y, Kosar A, Mishra C, Kuo C J and Schneider B 2005 Forced convective heat transfer across a pin fin micro heat sink Int. J. Heat Mass Transfer 48 3615-27

[3] Harris C, Kelly K, Tao Wang, McCandless A and Motakef S 2002 Fabrication, modeling, and testing of micro-cross-flow heat exchangers J. Microelectromech. Syst. 11 726-35

[4] Lerou P P P M, Venhorst G C F, Berends C F, Veenstra T T, Blom M, Burger J F, ter Brake $\mathrm{H} J \mathrm{M}$ and Rogalla $\mathrm{H}$ 2006 Fabrication of a micro cryogenic cold stage using MEMS-technology J. Micromech. Microeng. 16 1919-25

[5] Ackermann R A 1997 Cryogenic Regenerative Heat Exchangers (New York: Plenum) pp 15-58 chapter 2
[6] Ruhlich I and Quack H 1999 Investigations on regenerative heat exchangers Cryocoolers 10 265-74

[7] Radebaugh R and O'Gallagher A 2006 Regenerator operation at very high frequencies for microcryocoolers $A d v$. Cryogen. Eng. 51 1919-28

[8] Vanapalli S, Lewis M, Gan Z and Radebaugh R 2007120 Hz pulse tube cryocooler for fast cooldown to $50 \mathrm{~K}$ Appl. Phys. Lett. 90072504

[9] Radebaugh R 2005 Microscale heat transfer at low temperatures Microscale Heat Transfer Fundamentals and Applications (Berlin: Springer) pp 93-124

[10] Zukauskas and Ulinskas 1989 Heat transfer from tubes in cross flow Adv. Heat Transfer 8 72-160

[11] Kosar A, Mishra C and Peles Y 2005 Laminar flow across a bank of low aspect ratio micro pin fins J. Fluids Eng. 127 419-30

[12] Gary J, Daney D E and Radebaugh R 1985 A computational model for a regenerator Proc. 3rd Cryocooler Conf.: NIST Special Publication vol 698 pp 199-211

[13] Gary J and Radebaugh R 1991 An improved model for the calculation of regenerator performance (REGEN3.1) Proc. 4th Interagency Meeting on Cryocoolers: David Taylor Research Center Technical Report DTRC91/003 pp 165-76

[14] Kays W M and London A L 1964 Compact Heat Exchangers (New York: McGraw-Hill) chapters 1 and 7

[15] Blevins R D 1992 Applied Fluid Dynamics Handbook (Malabar, FL: Krieger) chapter 6

[16] Roychoudhury D G, Das S K and Sundararajan T 2002 Numerical simulation of laminar flow and heat transfer over banks of staggered cylinders Int. J. Numer. Methods Fluids 39 23-40 